\title{
Editoriali
}

\section{Developments in mental health policy in the United Kingdom}

\author{
JONATHAN BINDMAN, SARA DAVIES, RUTH TAYLOR, GRAHAM THORNICROFT
}

\section{INTRODUCTION}

The number of psychiatric hospital beds in England and Wales has fallen from more that 150,000 in 1955 to less than 40,000 in 1990 (Davidge et al., 1993), mirroring changes in the USA and Europe (Bachrach, 1986; Tansella, 1986).

The political climate of the 1980 s resulted in a greater emphasis on efficiency, accountability and management in public services, and resulting legislative changes affecting general health and social services have also profoundly affected UK mental health care. There have also been legislative and administrative changes specifically relating to the delivery of mental health care, and these have sought particularly to address public concerns about patients believed to be at risk of self harm or of causing harm to others (Davies \& Peck, 1994).

These changes have led to the development of community-based services, and also to innovation and experimentation. This paper will outline the UK health care system and describe policy changes which have affected mental health services. The structure of community mental health services will be described and some evaluations of experimental services will be discussed.

\section{HEALTH CARE IN THE UK}

The National Health Service (NHS) is a universal

\footnotetext{
Indirizzo per la corrispondenza: Dr. J. Bindman, PRiSM (Psychiatric Research in Service Measurement), Institute of Psychiatry, De Crespigny Park, London 8E5 8AZ (England).

Fax $(+44)$ 171-277.14.62.
}

health care system, funded through national taxation, and free at the point of delivery. The great majority of the population rely on it for all their health care, and in the field of mental health, no more than $6 \%$ of psychiatric inpatients are treated in private hospitals (Marks \& Thornicroft, 1990).

The NHS is hierarchically controlled, headed by a Minister and the government Department of Health, who oversee about 100 health purchasing authorities, each responsible for a population of about 500,000. Purchasing and providing functions, until recently the responsibility of a single health authority in each district, have now been separated as described below. Slightly different arrangements apply in different parts of Britain, and only UK law and English administration will be described.

General Practitioners (GPs) form the primary health care system, and $98 \%$ of the population are registered with a GP (Sharp \& Morrell, 1989). GPs make most of the referrals to the specialist hospital services, the secondary health care system, and therefore screen patients for these services. They see the bulk of psychiatric morbidity, especially non-psychotic disorders (Goldberg \& Huxley, 1992), and often share in the long-term care of patients with major mental illness (Tyrer et al., 1993).

Mental health services are provided both by the National Health Service, which accounted for $90 \%$ of mental health expenditure in 1992/3, and by local government social services departments, which accounted for the remaining $10 \%$ of the total of $£ 1.8$ billion (England and Wales; Audit Commission, 1994). In addition, numerous voluntary agencies contribute to the provision of social care, and also influence mental health policy and planning by advocating the needs of users of the services. 


\section{GENERAL HEALTH CARE POLICY}

The most important recent legislation that has affected general health and social services delivery in the UK is the 1990 NHS and Community Care Act (Thornicroft, 1994). The central element was the creation of an internal market in the NHS, intended to achieve greater efficiency by introducing competition. District Health Authorities were required to separate their traditional roles as purchasers and providers of health care, and develop as purchasing authorities. The Act allowed secondary care provider units (hospitals or other services) to become independently managed Trusts, with some of the freedoms of private businesses e.g. to borrow money and retain profits (Weich, 1994). Services are now purchased from providers by the purchasing authorities. At the primary care level, GPs may also become independent purchasers (fundholders), and receive funds to purchase hospital and community services as they wish (Kendrick, 1994), though this does not at present include psychiatric in-patient services.

The Act requires local social service and health authorities to agree community care plans for the social care needs of their local population, in consultation with users, carers and voluntary organisations (Smith \& Peck, 1994). It also introduces the concept of case management, which is the assessment of needs and planning of services for individuals. Health service case management practice includes direct care, but social services case managers are increasingly developing brokerage models (care management), where the case manager co-ordinates the provision of care by others.

The Act places a statutory duty on local social services to provide an individual needs assessment for people who require it (House of Commons, 1990). Tools have been developed to standardize this assessment for the severely mentally ill, and the Camberwell Assessment of Need (CAN) meets the statutory requirements for needs assessment which include giving equal weight to staff and users views, considering a comprehensive range of health and social needs, and assessing need separately from interventions (Phelan et al., 1995). ${ }^{1}$

\footnotetext{
${ }^{1}$ Copies of the Camberwell Assessment of Need are obtainable from PRiSM (Psychiatric Research in Service Measurement), Institute of Psychiatry, De Crespigny Park, Denmark Hill, London SE5 8AF, England.

Tel. $+44-171-919.2610$. Fax $+44-171-277.1462$
}

The Act has established the separation of purchaser and provider roles in both health and social services. The relationship between purchaser and provider is based on contracts, and clinicians in the UK are therefore becoming increasingly aware of the need to demonstrate to purchasers the outcomes for patients and the cost-effectiveness of the services that they provide.

\section{SECTORISATION OF MENTAL HEALTH SERVICES IN THE UK}

As in other countries in Europe, the development of sectors, in which all patients in a defined geographical area are served by a particular psychiatric team, has accompanied the development of community mental health services (Lindholm, 1983; Bennett, 1991).

Unlike elsewhere in Europe, however, sectorisation has not been centrally directed, but has occurred in an unplanned manner. A recent study found that $81 \%$ of District Health Authorities in Britain were sectorised, and most had become so since 1985 (Johnson \& Thornicroft, 1993). The lack of planning has led to variations in the size of sectors (from 25,000 to 180,000 ) and in the services provided by them. In the majority of sectorised districts a single team provides both acute and continuing care, but in others these functions are separated. The sector teams usually work during office hours, and rely on a central hospital based service at night, only $5 \%$ providing 24 hour emergency cover. Sectorised services are increasingly based outside the hospital, though in some districts services are organised on a sector principle but the staff and facilities are still hospital based (Johnson \& Thornicroft, 1993).

\section{MENTAL HEALTH POLICY}

In 1992, the government identified mental health as a priority area in its overall health strategy (Department of Health, 1993), and set targets for the health service of improving the health and social functioning of mentally ill people, and reducing suicide rates in the general population, and in the se- 
verely mentally ill in particular. Subsequent strategy documents have further emphasized the need for specialist mental health services to target those with severe mental illness (Department of Health, 1995).

Two incidents in 1992, one in which a man with schizophrenia was injured after climbing into a lions cage at London Zoo, and another in which a man was killed by a former psychiatric patient, resulted in intense public interest in the community care of people with severe mental illness (Ritchie, 1994). This interest has been maintained by a number of subsequent inquiries into incidents of homicide (Zito Trust, 1995), which have been widely regarded as indicating the failure of community care. Though neither research nor individual inquiries support such a broad conclusion (Royal College of Psychiatrists, 1996), a number of specific problems in the care of the severely mentally ill have been identified and are further discussed below. The government has responded to public concern with administrative measures to develop care registers, and with new mental health legislation.

\section{Care registers}

Case Registers of people with psychiatric illness were originally developed in the UK in the 1960s for the purposes of epidemiological research (Bamrah et al., 1991), and studies of service utilisation (Wing, 1984). More recently there has been the development of a new type of register designed to identify individuals and ensure continuity of care. In 1990 mental health services were instructed to implement a system of co-ordinating care, the Care Programme Approach (CPA). This requires that all patients should be assessed, and receive a key worker, a care plan, and regular reviews (Department of Health, 1990). Care Programme Registers developed locally to support this system.

The inquiries referred to above highlighted a number of problems in the care of people with severe mental illness, including inadequate communication between services, failure to maintain contact with patients, and inadequate risk assessment (Ritchie et. al., 1994). To address these, in 1994 mental health services were instructed to set up a further care register, the Supervision Register (National Health Service Management Executive, 1994). This is a local register of patients who are... at risk of committing serious violence or suicide, or of serious self neglect...as a result of severe and enduring mental ill- ness (Holloway, 1994). The register is intended to identify only those patients at greatest risk, to ensure that risks are assessed, and contact with patients maintained.

The Supervision Registers are still in the preliminary stages of development, and their effectiveness has not been evaluated. Though over 3000 patients in England were placed on them in the first year of operation, there are wide variations between providers in the numbers registered (National Health Service Management Executive, 1995). Different teams and psychiatrists probably have varying views on what constitutes a high degree of risk. Psychiatrists have strongly criticized the Supervision Registers, on several grounds including the uncertainty about their effectiveness in reducing risk, and the cost implications of administering them (Caldicott, 1994). User groups have criticized the use of registers on civil liberties grounds (MIND, 1991).

\section{Mental health legislation}

Having rejected suggestions for a new law allowing the compulsory medication of patients outside hospital (House of Commons, 1993), the government proposed instead limited amendments to the existing law, which will come into effect in 1996 (House of Lords, 1995). A new supervised discharge order has been created, which may be applied to a similar group of patients to those on the Supervision Register. The patient's psychiatrist and community nurse will be given powers to supervise the patient, most significantly the power to force an unwilling patient to attend a place of treatment, not necessarily a hospital. However, compulsory treatment can only be given after admitting the patient to hospital under the existing law. It has been suggested that the new law limits civil liberties but adds nothing useful to the existing law.

\section{EXPERIMENTAL MODELS AND EVALUATIVE RESEARCH}

While the effects of many of the changes in UK mental health services described above are unclear, a number of experimental services have been evaluated. A controlled study in South London (Muijen et al., 1992) compared comprehensive assertive 
home-based care with standard in/out-patient care for patients with severe mental illness. Though social and clinical outcomes were similar, patients' and relatives' satisfaction was higher in the group receiving home based care, and costs were lower. Once the experimental period ended, most gains were lost. The team concluded that further research would be needed to identify the effective components of home based care (Marks et al., 1994).

Another comparison of home-based care compared to routine hospital based care. in London found similar clinical and social outcomes (Burns et al., 1993a). Access to care was better in the group receiving early home assessments. The home-based service was more cost effective (Burns et al., 1993b), and it was felt that the service, based in existing community services, would be sustainable with adequate investment. A comparison of two psychiatric teams in Birmingham, UK, also found that treatment by a community-based service had similar social and clinical outcomes to the hospital based service, but that the community service was much preferred by relatives and was more effective at keeping patients in long term contact (Dean et al., 1993).

\section{CONCLUSION}

The experimental models suggest community based mental health services can be as efficacious as hospital based services, with increased patient and carer satisfaction. Some are more cost effective. However it has yet to be demonstrated that the benefits of experimental services can be generalized and sustained. Despite many years of continu- ous change, the transfer of mental health services into the community is far from complete, and the policies described are still not fully implemented (Audit Commission, 1994). The political response to concerns about failures of community care may lead to better targeting of services to those with severe mental illness, but policies designed to control rather than to care may prove counterproductive.

\section{REFERENCES}

Audit Commission (1994). Finding a Place: A Review of Mental Health Services for Adults. HMSO: London.
Bachrach L. (1986). Deinstitutionalisation: what do the numbers mean? Hospital and Community Psychiatry 37, 118-121.

Bamrah J.S., Freeman H.L. \& Goldberg D.P. (1991). Epidemiology of schizophrenia in Salford, 1974-84. Changes in an urban community over ten years. British Journal of Psychiatry 159, 802-810.

Bennett D. (1991). The International Perspective. In Community Psychiatry: The Principles (ed. D.H. Bennett and H.L. Freeman). Churchill Livingstone: Edinburgh.

Burns T., Beadsmore A., Bhat A.V., Oliver A. \& Mathers C. (1993a). A controlled trial of home-based acute psychiatric services. I: Clinical and social outcome. British Journal of Psychiatry $163,49-54$.

Burns T., Raftery J., Beadsmore A., McGuigan S. \& Dickson M. (1993b). A controlled trial of home-based acute psychiatric services. II: Treatment patterns and costs . British Journal of Psychiatry $163,55-61$.

Caldicott F. (1994) Supervision Registers: the College's response. Psychiatric Bulletin 18, 385-386.

Davidge M., Elias S., Jayes B., Wood K. \& Yates J. (1993). Survey of English Mental Illness Hospitals, March 1993. Inter-Authority Comparisons and Consultancy. Health Service Management Centre: Birmingham.

Davies S. \& Peck E. (1994). Recent government policy and legislation: an overview. Psychiatric Bulletin 18, 662-665.

Dean C., Phillips J., Gadd E.M., Joseph M. \& England S. (1993). Comparison of community based service with hospital based service for people with acute, severe psychiatric illness. British Medical Journal 307, 473-476.

Department of Health (1990). The Care Programme Approach for People with a Mental Illness Referred to the Specialist Psychiatric Services. DoH: London.

Department of Health (1993). The Health of the Nation. Key Area Handbook: Mental Illness. DoH: London.

Department of Health (1995). Building Bridges. A Guide to Arrangements for Inter-Agency Working for the Care and Protection of Severely Mentally Ill People. DoH: London.

Goldberg D. \& Huxley P. (1992). Common Mental Disorders. A Bio-Social Model. Routledge: London.

Holloway F. (1994). Supervision registers. Recent government policy and legislation. Psychiatric Bulletin 18, 593-596.

House of Commons (1990). The National Health Service and Community Care Act. HMSO: London.

House of Commons (1993). Community Supervision Orders. Health Committee 5th Report. Vol 1. HMSO: London.

House of Lords (1995). Mental Health (Patients in the Community) Bill. HMSO: London.

Johnson S. \& Thornicroft G. (1993). The sectorisation of psychiatric services in England and Wales. Social Psychiatry and Psychiatric Epidemiology 28, 45-47.

Kendrick T. (1994). Fund-holding and commissioning general practitioners: recent government policy and legislation. Psychiatric Bulletin 18, 538-540.

Lindholm H. (1983). Sectorised psychiatry. Acta Psychiatrica Scandinavica 67, Supplementum 304.

Marks I. \& Thornicroft G. (1990). Private psychiatric inpatient care. British Medical Journal 300, 892.

Marks I., Connolly J., Muijen M., Audini B., McNamee G. \& Lawrence R.E. (1994). Home-based versus hospital-based care for people with serious mental illness. British Journal of Psychiatry 165, 179-194.

MIND (1991). Minds Policy on Case Registers. Mind Policy Paper 1991. 
Muijen M., Marks I.M., Connolly J., Audini-B. \& McNamee-G. (1992). The Daily Living Program. Preliminary comparison of community versus hospital-based treatment for the seriously mentally ill facing emergency admission. British Journal of Psychiatry 160, 379-384.

National Health Service Management Executive (1994). Health Service Guidelines HSG (94)5.

National Health Service Management Executive (1995). Quarterly Monitoring Report, $Q 2$.

Phelan M., Slade M., Thornicroft G., Dunn G., Holloway F., Loftus L., Strathdee G., Wykes T. \& McCrone P. (1995). The Camberwell Assessment of Need (CAN): the validity and reliability of an instrument to assess the needs of the seriously mentally ill. British Journal of Psychiatry 167, 589-595

Ritchie J.H., Dick D. \& Lingham R. (1994). The Report of the Inquiry into the Care and Treatment of Christopher Clunis. HMSO: London.

Royal College of Psychiatrists (1996). Report of the Confidential Inquiry into Homicides and Suicides by Mentally Ill People. Royal College of Psychiatrists: London.

Sharp D. \& Morrell D. (1989). The psychiatry of general practice. In Scientific Approaches in Epidemiology and Social Psychia- try: Essays in Honour of Michael Shepherd (ed. P. Williams, G. Wilkinson and K. Rawnsley). Routledge: London.

Smith H. \& Peck E. (1994). A Process for Change: Developing Strategies for Mental Health Services. Occasional Paper No.3. Centre for Mental Health Services Development: London.

Tansella M. (1986). Community psychiatry without mental hospitals - the Italian experience: a review. Journal of the Royal Society of Medicine 79, 664-669.

Thornicroft G. (1994). The NHS and Community Care Act 1990. Psychiatric Bulletin 18, 13-17.

Tyrer P., Turner R. \& Johnson A. (1989). Integrated hospital and community psychiatric services and use of inpatient beds. British Medical Journal 299, 298-300.

Tyrer P., Higgs R. \& Strathdee G. (1993). Mental Health and Primary Care. A Changing Agenda. Gaskell \& The Mental Health Foundation: London.

Weich S. (1994). NHS Trusts. Recent government policy and legislation. Psychiatric Bulletin 18, 131-134.

Wing J.K. (1984). Collaboration between psychiatric case registers. Bulletin of the Royal College of Psychiatrists 8 .

Zito Trust (1995). Learning the Lessons. Zito Trust: London. 